\title{
Evaluation of polymorphisms in the sulfonamide detoxification genes NAT2, CYB5A, and CYB5R3 in patients with sulfonamide hypersensitivity
}

\author{
James Sacco, B.Pharm, PhDa, Mahmoud Abouraya, DVM, PhD ${ }^{\mathrm{a}}$, Alison Motsinger-Reif, \\ $\mathbf{P h D}^{\mathrm{b}}$, Steven Yale, $\mathbf{M D}^{\mathrm{c}}$, Catherine McCarty, $\mathrm{PhD}, \mathbf{M P H}^{\mathrm{c}}$, and Lauren Trepanier, DVM, $\mathbf{P h D}^{\mathrm{a}}$ \\ aDepartment of Medical Sciences, School of Veterinary Medicine, University of Wisconsin- \\ Madison \\ bBioinformatics Research Center; Department of Statistics, North Carolina State University, \\ Raleigh, NC \\ cMarshfield Clinic Research Foundation, Marshfield, Wisconsin
}

\section{Abstract}

Objective-To determine whether polymorphisms in the sulfonamide detoxification genes, $C Y B 5 A$ (encoding cytochrome $b_{5}$ ), CYB5R3 (encoding cytochrome $b_{5}$ reductase), or NAT2 (encoding $N$-acetyltransferase 2) were over-represented in patients with delayed sulfonamide drug hypersensitivity, compared to control patients that tolerated a therapeutic course of trimethoprimsulfamethoxazole without adverse event.

Methods-DNA from 99 non-immunocompromised patients with sulfonamide hypersensitivity that were identified from the Personalized Medicine Research Project at the Marshfield Clinic, and from 99 age-, race-, and gender-matched drug-tolerant controls, were genotyped for four CYB5A and five $C Y B 5 R 3$ polymorphisms, and for all coding NAT2SNPs.

Results-CYB5A and CYB5R3 SNPs were found at low allele frequencies (less than 3-4\%), which did not differ between hypersensitive and tolerant patients. NAT2 allele and haplotype frequencies, as well as inferred NAT2 phenotypes, also did not differ between groups (60\% vs. $59 \%$ slow acetylators). Finally, no difference in NAT2 status was found in a subset of patients with more severe hypersensitivity signs (drug reaction with eosinophilia and systemic symptoms; DRESS) compared to tolerant patients.

Conclusions-We found no evidence for a substantial involvement of these 9 CYBSA or $C Y B 5 R 3$ polymorphisms in sulfonamide HS risk, although minor effects cannot be completely ruled out. Despite careful medical record review and full re-sequencing of the NAT2 coding region, we found no association of $N A T 2$ coding alleles with sulfonamide hypersensitivity (predominantly cutaneous eruptions) in this adult Caucasian population.

\section{Keywords}

sulfamethoxazole; potentiated sulfonamides; drug hypersensitivity; $N$-acetyltransferase; cytochrome b5; hydroxylamine

Correspondence: Lauren A. Trepanier, School of Veterinary Medicine, University of Wisconsin-Madison, 2015 Linden Drive, Madison, WI 53706-1102, USA. Tel.: 608265 9022; fax: 608265 8020, latrepanier@ vetmed.wisc.edu.

Dr. McCarty's present affiliation is Essentia Institute of Rural Health, Duluth MN.

Dr. Abouraya's present affiliation is the FDA/Center for Veterinary Medicine in Bethesda, MD.

The authors have no conflicts of interest to declare. 


\section{Introduction}

Potentiated sulfonamide antibiotics, such as sulfamethoxazole in combination with trimethoprim (TMP-SMX), are a common cause of idiosyncratic delayed drug hypersensitivity reactions. ${ }^{[1,2]}$ Skin rash and fever, occurring five or more days after drug initiation, are the most frequent manifestations, although hepatopathy, blood dyscrasias, and involvement of other organ systems have also been reported. ${ }^{[3]}$ Notably, TMP-SMX is the leading cause of Stevens-Johnson syndrome and toxic epidermal necrolysis, associated with $30 \%$ mortality. ${ }^{[4]}$

SMX hypersensitivity affects about $3 \%$ of the general population, ${ }^{[3]}$ with an apparent familial predisposition in non-immunocompromised patients. ${ }^{\left[{ }^{5-7]}\right.}$ This suggests a genetic component to these adverse drug reactions. SMX hypersensitivity has been attributed to the generation of a hydroxylamine metabolite (SMX-HA). ${ }^{[8-10]}$ SMX-HA spontaneously oxidizes to its unstable nitroso derivative (SMX-NO), which forms tissue haptens; ${ }^{[11,12]}$ these haptens stimulate the production of anti-SMX antibodies and drug-specific cytotoxic $\mathrm{T}$ cells. ${ }^{[12-15]}$ SMX-HA is generated by CYP2C9 in the liver; ${ }^{[16]}$ however, high activity variants of this enzyme, which might enhance the risk of SMX hypersensitivity, have not been identified. ${ }^{[17]}$

One detoxification pathway for sulfonamides is $\mathrm{N}$-acetylation of the parent drug by $\mathrm{N}$ acetyltransferases (NATs), leading to an inactive metabolite that is eliminated in the urine. Polymorphisms in the NAT2 gene that lead to a defective "slow" $N$-acetylation phenotype are well described, and slow NAT2 phenotype and genotypes have been reported to be overrepresented in patients with SMX hypersensitivity. ${ }^{[18-22]}$ However, since slow NAT2 polymorphisms are found in about half of Caucasians and African Americans, these genotypes alone are not sufficient to lead to SMX hypersensitivity in most patients. ${ }^{\text {[23] }}$

Another detoxification pathway for sulfonamides that we have recently characterized is cytochrome $b_{5}$ (b5) and NADH cytochrome $b_{5}$ reductase (b5R). These enzymes reduce SMX-HA back to the non-reactive parent SMX, ${ }^{[24]}$ via a detoxification pathway that is 10 times more efficient than forward oxidation to SMX-HA. ${ }^{[16]}$ SMX-HA reduction by b5 and b5R varies more than 19-fold in human liver, and we have identified multiple promoter, coding, and 3' UTR polymorphisms in the genes encoding b5 (CYB5A) and b5R (CYB5R3) in subjects with low to undetectable hepatic SMX-HA reduction activities. ${ }^{[25]}$ Thus, defective polymorphisms in either $C Y B 5 A$ or $C Y B 5 R 3$ could lead to increased availability of SMX-HA for eventual hapten formation, and could contribute, along with slow NAT2 alleles, to the individual risk of sulfonamide hypersensitivity.

The primary aim of this study, therefore, was to determine whether polymorphisms in $C Y B 5 A$ or $C Y B 5 R 3$, along with slow NAT2 genotypes, were over-represented in nonimmunocompromised patients with sulfonamide hypersensitivity, compared to patients who tolerated a prescribed therapeutic course of TMP-SMX.

\section{Methods}

\section{Patient samples}

Medical records of patients enrolled in the Personalized Medicine Research Project (PMRP), ${ }^{[26]}$ a cohort of over 20,000 patients who receive their medical care at the Marshfield Clinic, Marshfield, WI, were searched electronically for a history of TMP-SMX administration or for a diagnosis of sulfonamide hypersensitivity. These patients have previously donated blood samples for a genomic DNA bank, and provided informed consent for the use of their samples for biomedical research, linked to de-identified medical records 
data. Marshfield Clinic Research Foundation staff individually reviewed medical records, using a structured abstraction form to identify patients with sulfonamide hypersensitivity (HS). Each case was adjudicated to ensure consistency and accuracy. The abstraction form included the following eligibility criteria: 1) administration of TMP-SMX for at least 5 days prior to the adverse event; ${ }^{[3]}$ 2) documentation of one or more new clinical signs after starting TMP-SMX, including fever with or without eosinophilia, skin rash, increases in liver enzyme activities, hyperbilirubinemia, blood dyscrasias, pneumonitis, myocarditis, aseptic meningitis, polyarthritis, acute interstitial nephritis, toxic epidermal necrolysis, or Stevens-Johnson syndrome; ${ }^{[3]} 3$ ) lack of other clinical explanation for the adverse event; 4) absence of other drugs being administered that are know to cause rash in patients; and 5) resolution of clinical signs with discontinuation of TMP-SMX and no other interventions or changes in other drug regimens. Patients with only gastrointestinal symptoms such as nausea, vomiting or diarrhea, ${ }^{[3]}$ or with acute anaphylactoid reactions, ${ }^{[27,28]}$ were excluded. Because some forms of immunosuppression, in particular AIDS, lead to a high acquired risk of SMX hypersensitivity, possibly independent of genotype, ${ }^{[17]}$ immunocompromised patients, including those with HIV infection or undergoing immunosuppressive therapy, were not eligible. These criteria together in the abstraction form were designed to yield a score of 6 or more, or "probable" adverse reaction, using the Naranjo Adverse Drug Reaction scale. ${ }^{[29]}$ Data from any records with questionable abstraction criteria were reviewed by two authors (LT and SY) to reach consensus; records with vague or conflicting information were eliminated from eligibility.

Control patients ("tolerant;" TOL) within PMRP that were prescribed TMP-SMX were enrolled sequentially from medical records in random order, to provide a comparable group to the HS patients based on race, gender, and decade of age when TMP-SMX was prescribed. Control patients must have been prescribed a course of TMP-SMX at a standard therapeutic daily dosage for at least 10 days, with adequate follow-up in the medical record to indicate that the drug was taken and tolerated without adverse event. Clinical and demographic variables, including age at dosing, gender, race, body weight, dosage, duration of treatment, and reason for TMP-SMX prescription (respiratory, urinary tract, or other soft tissue infection) were also abstracted. A sample size calculation, using a Chi-Square distribution and an $\alpha=0.05$, indicated that $100 \mathrm{HS}$ cases and $100 \mathrm{TOL}$ controls would provide at least $80 \%$ power to detect an odds ratio of 2.33 or higher for common alleles (minor allele frequency of 0.25 ), and 4.01 or higher for less frequent alleles (minor allele frequency of 0.04).

\section{Genotyping for CYB5A and CYB5R3 polymorphisms}

Samples were genotyped for four $C Y B 5 A$ single nucleotide polymorphisms (SNPs; c. $13 \mathrm{~T}>\mathrm{G}, \mathrm{c} .178 \mathrm{~A}>\mathrm{G},-389 \mathrm{G}>\mathrm{A}$, and $-382 \mathrm{C}>\mathrm{T}$ ), and five $C Y B 5 R 3 \mathrm{SNPs}(\mathrm{c} .890 \mathrm{G}>\mathrm{A}, \mathrm{I} 1+6$ $\mathrm{C}>\mathrm{T},-251 \mathrm{G}>\mathrm{T}, * 392 \mathrm{G}>\mathrm{C}$, and $* 863 \mathrm{~T}>\mathrm{C}$ ). These SNPs were previously identified in resequencing of the promoter, coding, and $3^{\prime}$ untranslated regions of $C Y B 5 A$ and $C Y B 5 R 3$ in more than 180 subjects, ${ }^{[25,30,31]}$ and were observed in association with decreased protein expression and/or low hepatic SMX-HA reduction activities in individual subjects. [25,30] The PCR-based Taqman Genotyping Assay (Applied Biosytems, Foster City, CA), through the University of Wisconsin Biotechnology Center, was utilized for most polymorphisms. SNPs that failed the Taqman assay were evaluated by pyrosequencing, using the $\mathrm{PSQ}^{\mathrm{TM}}$ 96MA System (Biotage AB, Uppsala, Sweden). Both SNP screening techniques were validated by running positive and negative genomic DNA controls from liver or breast samples, in which the allele of interest had been previously established by direct sequencing. ${ }^{[25,32]}$ 


\section{Resequencing for NAT2 polymorphisms}

$N A T 2$ is a small gene with an intronless coding region, ${ }^{[33]}$ for which multiple SNPs have been identified in association with low activity (http://louisville.edu/medschool/ pharmacology/consensus-human-arylamine-n-acetyltransferase-gene-nomenclature/). Therefore, the entire $N A T 2$ coding region was resequenced for each subject, using primers designed to the $5^{\prime}$ and $3^{\prime}$ flanking regions of the open reading frame in exon 2 (F: CATGTAAAAGGGATTCATGCAG; R: CGTGAGGGTAGAGAGGATATCTG, encompassing $5^{\prime}$ I1 -77 to $\left.3^{\prime} * 90\right)$. NAT2 coding sequences were analyzed for polymorphisms using open source DNA analysis software (Staden Package; http:// staden.sourceforge.net/). All identified coding polymorphisms were confirmed by direct review of sequencing chromatograms, and by re-amplification and re-sequencing to rule out experimental artifacts.

\section{Statistical analyses}

Clinical and demographic variables, to include age at dosing, sex, race, body weight, dosage, duration of treatment, and reason for TMP-SMX prescription (respiratory, urinary tract, or other soft tissue infection) were compared between groups using a Mann Whitney $\mathrm{U}$ test or chi-square statistic, as appropriate. Prior to association analysis, genotypes were screened using quality control filters; SNPs were checked for genotyping efficiency (such that only genotypes or individuals with missing data rates less than 5\% were included) and tested for deviation from genotype proportions expected under Hardy-Weinberg equilibrium (HWE) conditions using Fisher's exact tests. Allele frequencies for CYB5A,CYB5R3, and NAT2 variants in HS patients were compared to those in control patients using Chi square or Fisher's exact tests, depending on the expected number of observations in the contingency table cells; a Bonferroni correction for the number of tests was used to correct with multiple comparisons (the alpha level cut-off for significance was adjusted based on the number of tests performed). In addition, interactions among genotypes in relation to SMX hypersensitivity risk were evaluated using Multifactor Dimensionality Reduction, a commonly used data-mining approach designed to detect gene-gene and gene-environment interactions. ${ }^{[3,35]}$ The quality control and univariate analyses were performed in Stata v11, and the MDR analysis was performed in R, using the MDR.R package. ${ }^{[36]}$

For $N A T 2$, haplotypes were assigned using standard NAT2 haplotype nomenclature ((http:// louisville.edu/medschool/pharmacology/consensus-human-arylamine-n-acetyltransferasegene-nomenclature/). A Fisher's exact test was then performed to test for association between NAT2 haplotype and HS status; rare haplotypes with less than 5 observations in the whole dataset were collapsed into a single category for analyses. Finally, individual patients were assigned a NAT2 phenotype using a public web server that utilizes pattern recognition to infer phenotype from genotypes at each of 6 polymorphic NAT2 coding sites $(282,341$, 481, 590, 803, and 857; nat2pred.rit.albany.edu). ${ }^{[37]}$ Prevalence of inferred phenotypes (fast, intermediate, or slow acetylator) were then compared between HS and TOL patients using Fisher's exact tests.

\section{Results}

\section{Patient demographics}

Ninety-nine HS patients were available for study. The most common documented clinical signs of HS were rash, fever, and eosinophilia, which were noted a median of 8.0 days after starting TMP-SMX (Table 1). Sixteen patients (16\%) had adequate data reported to meet the criteria for DRESS (drug reaction with eosinophilia and systemic symptoms), defined as 3 or more of the following: acute rash, fever, lymphadenopathy, involvement of an internal organ, and blood count abnormalities (lymphopenia or lymphocytosis, eosinophilia, or 
thrombocytopenia). ${ }^{[38]}$ Only one HS patient was re-challenged with TMP-SMX, and this patient also developed skin rash with re-exposure. Most medical records did not have an adequate family history regarding sulfonamide hypersensitivity; of 19 patients queried, one reported both a sister and a mother affected.

Ninety-nine control (TOL) patients were also enrolled. Thirty of these tolerant patients were prescribed an additional second course of TMP-SMX without adverse event. Dosage of TMP-SMX, body weight, and median duration of prescription (10 days) were not different between groups (Table 1). However, significantly fewer HS patients were prescribed TMPSMX for soft tissue infections (2\%) compared to tolerant patients (15\%; $\mathrm{P}=0.0015)$.

There were no significant differences between TOL and HS patients with regard to age at treatment, race, or sex, as these were controlled for in our matching protocol. Eighty-two of the HS patients were female (82.8\%), which was significantly higher than the $69.3 \%$ female prevalence in the larger PMRP database of patients that were prescribed TMP-SMX without recorded adverse event $(n=939 ; P=0.017)$.

\section{CYB5A and CYB5R3 genotyping}

No genotypes or individuals were removed based on quality control checks (no missing data for more than 5\% of subjects, and all $\mathrm{P}$ values from HWE tests $>0.05$ ). All of the 4 CYB5A SNPs were found at low allele frequencies (less than $4 \%$ of patients in both groups), and none were found at significantly different frequencies between HS and TOL patients (Table $2 ; \mathrm{P} \geq 0.17$ ). The $5 C Y B 5 R 3$ SNPs were also found at low allele frequencies (less than $3 \%$ of patients in both groups), and were also not different between groups (Table 2; $\mathrm{P} \geq 0.37$ ).

\section{NAT2 re-sequencing}

Eight SNP's were identified during resequencing of the NAT2 coding exon across all individuals. A novel SNP, NAT2 246C >T, was found in only one individual in the heterozygous state. The other seven SNPs were found with allele frequencies ranging from 0.005 to 0.747 (Table 3). However, there were no significant differences in minor allele, genotype, or haplotype frequencies between HS and TOL patients (Bonferroni adjusted rejection criteria $=0.007)$. Further, there were no detectable interactions among $C Y B 5 A$, CYB5R3, and NAT2 genotypes using Multifactor Dimensionality Reduction testing (largest accuracy for any model was $55.05 \%, \mathrm{P}<0.71)$.

Individual patients were assigned a NAT2 phenotype using a public web server that utilizes pattern recognition to infer NAT2 phenotype from genotypes at each of 6 polymorphic coding sites $\left(282,341,481,590,803\right.$, and 857; nat2pred.rit.albany.edu). ${ }^{[37]}$ A majority of HS patients were predicted to be slow acetylators (60\%, 59 of 99), which was not different from TOL patients (59\%, 58 of 99). When patients with DRESS were analyzed separately, there were still no differences in predicted NAT2 phenotypes between these more severely affected patients (63\% slow acetylators) and TOL patients (59\%). A post hoc power calculation for this subset of patients (using the same assumptions as described for the primary outcome power calculations) indicated that the current study had $80 \%$ power to detect odds ratios of 4.26 or higher for common NAT2 alleles (MAF $\geq 0.25$ ) in patients with DRESS, but only 7.18 or higher for lower frequency variants (MAF $\geq 0.04$ ).

\section{Discussion}

We hypothesized that defective SNPs in CYBSA and CYB5R3, along with slow NAT2 genotypes, would be associated with an increased risk of SMX drug hypersensitivity. We addressed this hypothesis by retrospectively identifying patients with a diagnosis of SMX hypersensitivity through the Personalized Medicine Research Project at Marshfield Clinic, 
and by comparing allele frequencies between HS and TOL patients for $9 C Y B 5 A$ and CYB5R3 polymorphisms, previously observed in association with low individual SMX-HA reduction and/or protein expression in genotype-phenotype surveys. ${ }^{[25,30]}$ In addition, we re-sequenced the $N A T 2$ coding region and compared allele, genotype, and haplotype frequencies between HS and TOL patients, as well as potential interactions among $C Y B 5 A$, $C Y B 5 R 3$, and NAT2 genotypes and HS outcome.

Most of the HS patients were female (83\%), which was significantly higher than the percentage of patients in the PMRP database that were prescribed TMP-SMX without adverse event (69\% female). A prospective study of more than 1,100 TMP-SMX prescriptions reported that $11 \%$ of women, but only $5 \%$ of men, developed skin rashes, [39] and a recent Thai study of cutaneous reactions to sulfonamide antibiotics reported a female:male ratio of 1.5 to 1 ; however, this latter result was not adjusted for the number of prescriptions made by gender. ${ }^{[40]}$ Conversely, a smaller prospective study of 359 SMX prescriptions found no gender difference in the incidence of "allergic" reactions, although specific diagnostic criteria were not given, ${ }^{[41]}$ and a retrospective study of 969 sulfonamide HS patients and 19,257 tolerant controls found no gender differences, although diagnostic codes for both acute and delayed HS were combined in the analysis. ${ }^{[42]}$ Therefore, it is unclear whether our findings represent a true gender predisposition for delayed SMX HS in this population, or result from unidentified co-morbidities or reporting bias.

We found that most $C Y B 5 A$ and $C Y B 5 R 3$ polymorphisms were uncommon in the control population of TOL patients. These findings are consistent with our previous observations in histologically normal human liver and breast tissue, in which non-synonymous polymorphisms in either gene were found at relatively low allele frequencies in healthy Caucasians. ${ }^{[25,31]}$ In the present study, we further found a similarly low prevalence of $C Y B 5 A$ and $C Y B 5 R 3$ polymorphisms in patients with sulfonamide HS; in addition, all $C Y B 5 A$ and $C Y B 5 R 3$ variants, when observed, were in the heterozygous state. This may reflect evolutionary pressure to conserve the function of this pathway, which has an important endogenous role in maintaining hemoglobin in its functional, reduced state. ${ }^{[43-45]}$ We did not fully re-sequence both genes in the HS and TOL patients, however, so we may have missed one or more important polymorphisms that were unique to HS patients. In addition, our matching protocol did not allow us to detect any interactions between sex or age at the time of adverse event, with any of the genotypes. Our sample size was able to detect odds ratios of 2.33 or higher for common alleles, and 4.01 or higher for low allele frequencies (i.e. MAFs of 0.04), although many of our $C Y B 5 A$ and $C Y B 5 R 3$ MAFs were even lower than this threshold. Based on the allele with the largest apparent divergence in MAFs between groups (-382C>T; MAFs of 0.035 in HS and 0.010 in TOL), we would have needed 530 patients with sulfonamide HS and 530 tolerant controls to show this to be a significant risk factor, with $80 \%$ power. However, given the low MAFs even in the affected patients, this and the other $C Y B 5 A$ and $C Y B 5 R 3$ alleles that we tested are unlikely to have even a modest impact on sulfonamide HS outcome in the general (Caucasian) population.

NAT2 polymorphisms were found in TOL control patients with allele frequencies that were similar to those previously reported in Caucasians, ${ }^{[23,46,47]}$ and there were no significant differences in allele or genotype frequencies between TOL and HS patients. Further, when our patients were assigned an inferred NAT2 phenotype, the proportion of HS patients with slow acetylator status (60\%) was not significantly different from TOL patients (59\%). This is in contrast to two earlier small phenotyping studies using caffeine as a probe, which showed a high proportion of HS patients with the slow acetylator phenotype (90$100 \%) .{ }^{[6,18]}$ Most of these patients were children, and phenotype prevalence was compared to adult control populations ( $55 \%$ slow acetylator prevalence). ${ }^{[6,18]}$ Young children may have discordant acetylation phenotype and genotype due to differences in caffeine 
disposition, and a later study showed that $23 \%$ of children with wild type NAT2 genotypes were falsely assigned to slow acetylator status based on caffeine administration. [48] Therefore, age-related discordance between acetylator genotype and phenotype status could explain, in part, the differences between our findings and previous phenotyping studies.

Other studies have looked directly at NAT2 genotype and sulfonamide HS (Table 4). No associations with sulfonamide HS were found for NAT2 alleles in two studies of HIVinfected patients, ${ }^{[17,49]}$ which is consistent with the hypothesis that the acquired high risk of SMX HS in this population may involve environmental factors. ${ }^{[50]}$ In nonimmunocompromised patients, the synonymous $N A T 2$ SNP $481 \mathrm{C}>\mathrm{T}$ was found in 14 of 18 patients (78\%) with severe bullous skin eruptions from sulfonamide antibiotics, ${ }^{[20]}$ and with a higher allele frequency in 14 infants with sulfonamide HS compared to 7 drug-tolerant babies. ${ }^{[22]}$ A later study in 29 children with TMP-SMX HS found a significantly higher prevalence of slow $590 \mathrm{G}>\mathrm{A}$ and $857 \mathrm{G}>\mathrm{A}$ alleles, compared to 19 drug-tolerant patients, and no HS patients had a wild type $N A T 2$ genotype. ${ }^{[21]}$ Finally, in Japanese patients with systemic lupus erythematous, the wild type $N A T 2 * 4$ allele was significantly less common in 18 patients that developed drug HS compared to patients that tolerated TMP-SMX. ${ }^{[19]}$ In all of these NAT2 genotyping studies, the number of HS patients was relatively small, and a relatively high proportion of patients had systemic signs other than simple rash, to include hepatopathy, blood dyscrasias, and bullous skin eruptions (69-100\% of affected patients). ${ }^{[19-22]}$ Most of the patients in our study had SMX HS that was limited to cutaneous involvement, and we could have missed NAT2 genotype associations in the subset of patients with more severe systemic manifestations of sulfonamide HS.

In addition, there is always a concern that some HS patients in our study, as well as in previous studies without complete medical record review, may have developed cutaneous eruptions due to other, unidentified causes, and were therefore misclassified. Our study design took advantage of the Personalized Medicine Research Project (PMRP) at the Marshfield Clinic, Marshfield, WI, for which DNA samples have been banked, with informed consent, from more than 20,000 patients under Marshfield Clinic care. These samples are linked to complete medical records that follow patients for, in some cases, decades. However, most patients were not re-challenged with TMP-SMX to confirm the diagnosis of sulfonamide hypersensitivity. Although this is considered the gold standard for confirmation of an idiosyncratic reaction, it is typically not pursued because of risk to the patient. In order to enhance the quality of our study population, we performed complete chart reviews rather than relying on diagnostic codes, and adjudicated all cases. This allowed us to categorize patients using the Naranjo Adverse Drug Reaction scale prior to inclusion, ${ }^{[29]}$ including only patients with a "probable" or higher score, in an attempt to minimize misclassification.

Overall, our data do not support an association between these candidate $C Y B 5 A$ and CYB5R3 SNPs, or NAT2 coding SNPs, with sulfonamide HS in this population of Caucasian patients with primarily cutaneous eruptions. While our study was adequately powered for moderate effects, we had limited power to detect very small effect sizes, especially for rare variants, and we cannot rule out minor contributions of these alleles. In addition, evaluation of larger group of patients with more severe manifestations of SMX HS is indicated. Follow-up studies are planned to further examine genetic risk of SMX HS from a broader perspective, using genome wide association techniques in an expanded group of patients from the PMRP and other populations. 


\section{Acknowledgments}

This study was supported by grant R01 GM61753 from the National Institutes of Health, and by a UW Institute for Clinical and Translational Research pilot grant, funded through an NCRR/NIH Clinical and Translational Science Award, 1UL1RR025011. Dr. Abouraya was supported by a fellowship from Elanco Animal Health and by T32 training grant RR023916 from the National Institutes of Health. The authors would like to thank Ms. Terrie Kitchner, Marshfield Clinic Research Foundation, for data abstraction; Marie Adams, University of WisconsinMadison Biotechnology Center, for Taqman genotyping; Dr. Elim Lau at the University of Wisconsin Carbone Comprehensive Cancer Center for performing pyrosequencing (facilities supported by NIH/NCI P30 CA014520); and Jasmine Dockery for assistance with NAT2 resequencing (Ms. Dockery was supported by National Science Foundation grant DBI-1063085).

\section{References}

1. Morelli JG, Tay YK, Rogers M, Halbert A, Krafchik B, Weston WL. Fixed drug eruptions in children. J Pediatr. 1999; 134:365-367. [PubMed: 10064679]

2. Raksha MP, Marfatia YS. Clinical study of cutaneous drug eruptions in 200 patients. Indian J Dermatol Venereol Leprol. 2008; 74:80. [PubMed: 18193504]

3. Cribb AE, Lee BL, Trepanier LA, Spielberg SP. Adverse reactions to sulphonamide and sulphonamide-trimethoprim antimicrobials: clinical syndromes and pathogenesis. Adv Drug Reactions Toxicol Rev. 1996; 15:9-50.

4. Ortiz J, Horn M, Peterson H. Toxic epidermal necrolysis-case report and review of the literature. Ann Plast Surg. 1982; 9:249-253. [PubMed: 7137822]

5. Neuman M, Malkiewicz I, Shear N. A novel lymphocyte toxicity assay to assess drug hypersensitivity syndromes. Clin Biochem. 2000; 33:517-524. [PubMed: 11124336]

6. Shear NH, Spielberg SP, Grant DM, Tang BK, Kalow W. Differences in metabolism of sulfonamides predisposes to idiosyncratic toxicity. Ann Intern Med. 1986; 105:179-184. [PubMed: 3729200]

7. Wolkenstein P, Charue D, Laurent P, Revuz J, Roujeau J-C, Bagot M. Metabolic predisposition to cutaneous adverse drug reactions: role in toxic epidermal necrolysis caused by sulfonamides and anticonvulsants. Arch Dermatol. 1995; 131:544-551. [PubMed: 7741540]

8. Cribb AE, Miller M, Leeder JS, Hill J, Spielberg SP. Reactions of the nitroso and hydroxylamine metabolites of sulfamethoxazole with reduced glutathione: implications for idiosyncratic toxicity. Drug Metab Disp. 1991; 19:900-906.

9. Reilly TP, Bellevue FH, Woster PM, Svensson CK. Comparison of the in vitro cytotoxicity of hydroxylamine metabolites of sulfamethoxazole and dapsone. Biochem Pharmacol. 1998; 55:803810. [PubMed: 9586952]

10. Roychowdhury S, Vyas PM, Svensson CK. Formation and uptake of arylhydroxylaminehaptenated proteins in human dendritic cells. Drug Metab Dispos. 2007; 35:676-681. [PubMed: 17220235]

11. Manchanda T, Hess D, Dale L, Ferguson S, Rieder M. Haptenation of sulfonamide reactive metabolites to cellular proteins. Mol Pharmacol. 2002; 62:1011-1026. [PubMed: 12391263]

12. Naisbitt D, Gordon S, Pirmohamed M, Burkhart C, Cribb A, Pichler W, et al. Antigenicity and immunogenicity of sulphamethoxazole: demonstration of metabolism-dependent haptenation and T-cell proliferation in vivo. Br J Pharmacol. 2001; 133:295-305. [PubMed: 11350866]

13. Farrell J, Naisbitt D, Drummond N, Depta J, Vilar F, Pirmohamed M, et al. Characterization of sulfamethoxazole and sulfamethoxazole metabolite-specific T-cell responses in animals and humans. J Pharmacol Exp Ther. 2003; 306:229-237. [PubMed: 12676884]

14. Gill HJ, Hough SJ, Naisbitt DJ, Maggs JL, Kitteringham NR, Pirmohamed M, et al. The relationship between the disposition and immunogenicity of sulfamethoxazole in the rat. $\mathrm{J}$ Pharmacol Exp Ther. 1997; 282:795-801. [PubMed: 9262343]

15. Naisbitt D, Farrell J, Gordon S, Maggs J, Burkhart C, Pichler W, et al. Covalent binding of the nitroso metabolite of sulfamethoxazole leads to toxicity and major histocompatibility complexrestricted antigen presentation. Mol Pharmacol. 2002; 62:628-637. [PubMed: 12181439] 
16. Cribb AE, Spielberg SP, Griffin GP. N4-hydroxylation of sulfamethoxazole by cytochrome P450 of the cytochrome $\mathrm{P} 4502 \mathrm{C}$ subfamily and reduction of sulfamethoxazole hydroxylamine in human and rat hepatic microsomes. Drug Metab Disp. 1995; 23:406-414.

17. Pirmohamed M, Alfirevic A, Vilar J, Stalford A, Wilkins EG, Sim E, et al. Association analysis of drug metabolizing enzyme gene polymorphisms in HIV-positive patients with co-trimoxazole hypersensitivity. Pharmacogenetics. 2000; 10:705-713. [PubMed: 11186133]

18. Rieder MJ, Shear NH, AK, Tang BK, Spielberg SP. Prominence of slow acetylator phenotype among patients with sulfonamide hypersensitivity reactions. Clin Pharmacol Ther. 1991; 49:1317. [PubMed: 1988235]

19. Soejima M, Sugiura T, Kawaguchi Y, Kawamoto M, Katsumata Y, Takagi K, et al. Association of the diplotype configuration at the $\mathrm{N}$-acetyltransferase 2 gene with adverse events with cotrimoxazole in Japanese patients with systemic lupus erythematosus. Arthritis Res Ther. 2007; 9:R23. [PubMed: 17335581]

20. Wolkenstein P, Carriere V, Charue D, Bastuji-Garin S, Revuz J, Roujeau J, et al. A slow acetylator genotype is a risk factor for sulphonamide-induced toxic epidermal necrolysis and StevensJohnson syndrome. Pharmacogenetics. 1995; 5:255-258. [PubMed: 8528274]

21. Zielinska E, Niewiarowski W, Bodalski J. The arylamine N-acetyltransferase (NAT2) polymorphism and the risk of adverse reactions to co-trimoxazole in children. Eur J Clin Pharmacol. 1998; 54:779-785. [PubMed: 9923584]

22. Zielinska E, Niewiarowski W, Bodalski J, Rebowski G, Skretkowicz J, Mianowska K, et al. Genotyping of the arylamine $\mathrm{N}$-acetyltransferase polymorphism in the prediction of idiosyncratic reactions to trimethoprim-sulfamethoxazole in infants. Pharm World Sci. 1998; 20:123-130. [PubMed: 9618736]

23. Lin HJ, Han CY, Lin BK, Hardy S. Slow acetylator mutations in the human polymorphic Nacetyltransferase gene in 786 Asians, blacks, Hispanics, and whites: application to metabolic epidemiology. Am J Hum Genet. 1993; 52:827-834. [PubMed: 8460648]

24. Kurian J, Bajad S, Miller J, Chin N, Trepanier L. NADH cytochrome $b_{5}$ reductase and cytochrome $\mathrm{b}_{5}$ catalyze the microsomal reduction of xenobiotic hydroxylamines and amidoximes in humans. $\mathrm{J}$ Pharmacol Exp Ther. 2004; 311:1171-1178. [PubMed: 15302896]

25. Sacco JC, Trepanier LA. Cytochrome b5 and NADH cytochrome b5 reductase: genotypephenotype correlations for hydroxylamine reduction. Pharmacogenet Genomics. 2010; 20:26-37. [PubMed: 19997042]

26. McCarty C, Wilke R, Giampietro P, Wesbrook S, Caldwell M. Marshfield Clinic Personalized Medicine Research Project (PMRP): design, methods and recruitment for a large, populationbased biobank. Personalized Medicine. 2005; 2:49-79.

27. Gruchalla RS, Sullivan TJ. Detection of human IgE to sulfamethoxazole by skin testing with sulfamethoxazoyl-poly-L-tyrosine. J Allergy Clin Immunol. 1991; 88:784-792. [PubMed: 1955637]

28. Harle DG, Baldo BA, Wells JV. Drugs as allergens: detection and combining site specificities of IgE antibodies to sulfamethoxazole. Mol Immunol. 1988; 25:1347-1354. [PubMed: 3237218]

29. Naranjo C, Busto U, Sellers E, Sandor P, Ruiz I, Roberts E, et al. A method for estimating the probability of adverse drug reactions. Clin Pharmacol Ther. 1981; 30:239-245. [PubMed: 7249508]

30. Kurian JR, Longlais BJ, Trepanier LA. Discovery and characterization of a cytochrome b5 variant in humans with impaired hydroxylamine reduction capacity. Pharmacogenet Genomics. 2007; 17:597-603. [PubMed: 17622936]

31. Rhoads K, Sacco JC, Drescher N, Wong A, Trepanier LA. Individual variability in the detoxification of carcinogenic arylhydroxylamines in human breast. Toxicol Sci. 2011; 121:245256. [PubMed: 21447608]

32. Rhoads K, Sacco JC, Drescher N, Wong A, Trepanier LA. Individual variability in the detoxification of carcinogenic arylhydroxylamines in human breast. Toxicological sciences: an official journal of the Society of Toxicology. 2011; 121:245-256. [PubMed: 21447608] 
33. Boukouvala S, Sim E. Structural analysis of the genes for human arylamine N-acetyltransferases and characterisation of alternative transcripts. Basic Clin Pharmacol Toxicol. 2005; 96:343-351. [PubMed: 15853926]

34. Ritchie MD, Hahn LW, Roodi N, Bailey LR, Dupont WD, Parl FF, et al. Multifactordimensionality reduction reveals high-order interactions among estrogen-metabolism genes in sporadic breast cancer. Am J Hum Genet. 2001; 69:138-147. [PubMed: 11404819]

35. Ritchie MD, Motsinger AA. Multifactor dimensionality reduction for detecting gene-gene and gene-environment interactions in pharmacogenomics studies. Pharmacogenomics. 2005; 6:823834. [PubMed: 16296945]

36. Winham SJ, Motsinger-Reif AA. An R package implementation of multifactor dimensionality reduction. BioData Min. 2011; 4:24. [PubMed: 21846375]

37. Kuznetsov IB, McDuffie M, Moslehi R. A web server for inferring the human Nacetyltransferase-2 (NAT2) enzymatic phenotype from NAT2 genotype. Bioinformatics. 2009; 25:1185-1186. [PubMed: 19261719]

38. Kardaun SH, Sidoroff A, Valeyrie-Allanore L, Halevy S, Davidovici BB, Mockenhaupt M, et al. Variability in the clinical pattern of cutaneous side-effects of drugs with systemic symptoms: does a DRESS syndrome really exist? Br J Dermatol. 2007; 156:609-611. [PubMed: 17300272]

39. Jick H. Adverse reactions to trimethoprim-sulfamethoxazole in hospitalized patients. Rev Infect Dis. 1982; 4:426-428. [PubMed: 6981160]

40. Chantachaeng W, Chularojanamontri L, Kulthanan K, Jongjarearnprasert K, Dhana N. Cutaneous adverse reactions to sulfonamide antibiotics. Asian Pac J Allergy Immunol. 2011; 29:284-289. [PubMed: 22053600]

41. Koch-Weser J, Sidel V, Dexter M, Parish C, Finer D, Kanarek P. Adverse reactions to sulfosoxazole, sulfamethoxazole, and nitrofurantoin. Manifestations and specific reaction rates during 2,118 courses of therapy. Archives of Internal Medicine. 1971; 128:399-404. [PubMed: 4255247]

42. Strom B, Schinnar R, Apter A, Margolis D, Lautenbach E, Hennessy S, et al. Absence of crossreactivity between sulfonamide antibiotics and sulfonamide nonantibiotics. N Engl J Med. 2003; 349:1628-1635. [PubMed: 14573734]

43. Hultquist D, Passon P. Catalysis of methaemoglobin reduction by erythrocyte cytochrome b5 and cytochrome b5 reductase. Nature New Biol. 1971; 229:252-254. [PubMed: 4324110]

44. Kitao T, Sugita Y, Yoneyama Y, Hattori K. Methemoglobin reductase (cytochrome b5 reductase) deficiency in congenital methemoglobinemia. Blood. 1974; 44:879-884. [PubMed: 4138943]

45. Hegesh E, Hegesh J, Kaftory A. Congenital methemoglobinemia with a deficiency of cytochrome b5. N Eng J Med. 1986; 314:757-761.

46. Cascorbi I, Drakoulis N, Brockmoller J, Maurer A, Sperling K, Roots I. Arylamine Nacetyltransferase (NAT2) mutations and their allelic linkage in unrelated Caucasian individuals: correlation with phenotypic activity. Am J Hum Genet. 1995; 57:581-592. [PubMed: 7668286]

47. Teixeira RL, Miranda AB, Pacheco AG, Lopes MQ, Fonseca-Costa J, Rabahi MF, et al. Genetic profile of the arylamine $\mathrm{N}$-acetyltransferase 2 coding gene among individuals from two different regions of Brazil. Mutat Res. 2007; 624:31-40. [PubMed: 17509624]

48. Zielinska E, Bodalski J, Niewiarowski W, Bolanowski W, Matusiak I. Comparison of acetylation phenotype with genotype coding for N-acetyltransferase (NAT2) in children. Pediatr Res. 1999; 45:403-408. [PubMed: 10088662]

49. Alfirevic A, Stalford A, Vilar F, Wilkins E, Park B. Slow acetylator phenotype and genotype in HIV-positive patients with sulphamethoxazole hypersensitivity. Br J Clin Pharmacol. 2003; 55:158-165. [PubMed: 12580987]

50. Pirmohamed M. Genetic factors in the predisposition to drug-induced hypersensitivity reactions. AAPS J. 2006; 8:E20-26. [PubMed: 16584129] 
Table 1

Patient demographics for sulfonamide hypersensitive and sulfonamide tolerant patients enrolled from the Marshfield Clinic Personalized Medicine Research Project.

\begin{tabular}{|c|c|c|}
\hline & Hypersensitive (n = 99) & Tolerant $(\mathbf{n}=99)$ \\
\hline Median age at dosing 1 & 38.5 years (range, 1.1 to 81.6 years) & 39.3 years (range, 8.5 to 87.7 years) \\
\hline Gender 1 & $\begin{array}{l}82 \text { females } \\
17 \text { males }\end{array}$ & $\begin{array}{l}82 \text { females } \\
17 \text { males }\end{array}$ \\
\hline Race $^{1}$ & $\begin{array}{l}96 \text { Caucasians } \\
3 \text { Native Americans }\end{array}$ & $\begin{array}{l}97 \text { Caucasians } \\
1 \text { Native American } \\
1 \text { Race not specified }\end{array}$ \\
\hline Median body weight & $80 \mathrm{~kg}$ (range, 13 to $124 \mathrm{~kg}$ ) & $77 \mathrm{~kg}$ (range, 27 to $150 \mathrm{~kg}$ ) \\
\hline Reason for prescription & $\begin{array}{l}\text { Respiratory infection }(62 \%) \\
\text { Urinary tract infection }(36 \%) \\
\text { Other soft tissue infection }(2 \%)\end{array}$ & $\begin{array}{l}\text { Respiratory infection }(60 \%) \\
\text { Urinary tract infection }(25 \%) \\
\text { Other soft tissue infection }(15 \%)\end{array}$ \\
\hline Median dosage of TMP-SMX & $24.1 \mathrm{mg} / \mathrm{kg} /$ day (range, 10.3 to $37.5 \mathrm{mg} / \mathrm{kg} /$ day) & $25.0 \mathrm{mg} / \mathrm{kg} /$ day (range, 13.0 to $71.0 \mathrm{mg} / \mathrm{kg} /$ day) \\
\hline Median duration of prescription & 10 days (range, 7 to 42 days) & 10 days (range, 10 to 30 days) \\
\hline Median time to adverse event & 8.0 days (range, 5 to 21 days) & NA \\
\hline Adverse event ( $\%$ patients affected $)$ & $\begin{array}{l}\text { Rash }(94.9 \%) \\
\text { Fever }(18.2 \%) \\
\text { DRESS } 2(16.2 \%) \\
\text { Eosinophilia }(15.2 \%) \\
\text { Thrombocytopenia }(9.1 \%) \\
\text { Neutropenia }(5.1 \%) \\
\text { Anemia }(4.4 \%) \\
\text { Increases in liver enzymes or bilirubin }(2.0 \%) \\
\text { Stevens-Johnson syndrome }(1.0 \%) \text {. }\end{array}$ & NA \\
\hline
\end{tabular}

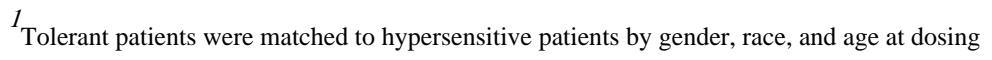

2 Drug reaction with eosinophilia and systemic symptoms, defined as 3 or more of the following: acute rash, fever, lymphadenopathy, involvement of an internal organ, and blood count abnormalities (lymphopenia or lymphocytosis, eosinophilia, or thrombocytopenia). [38] 


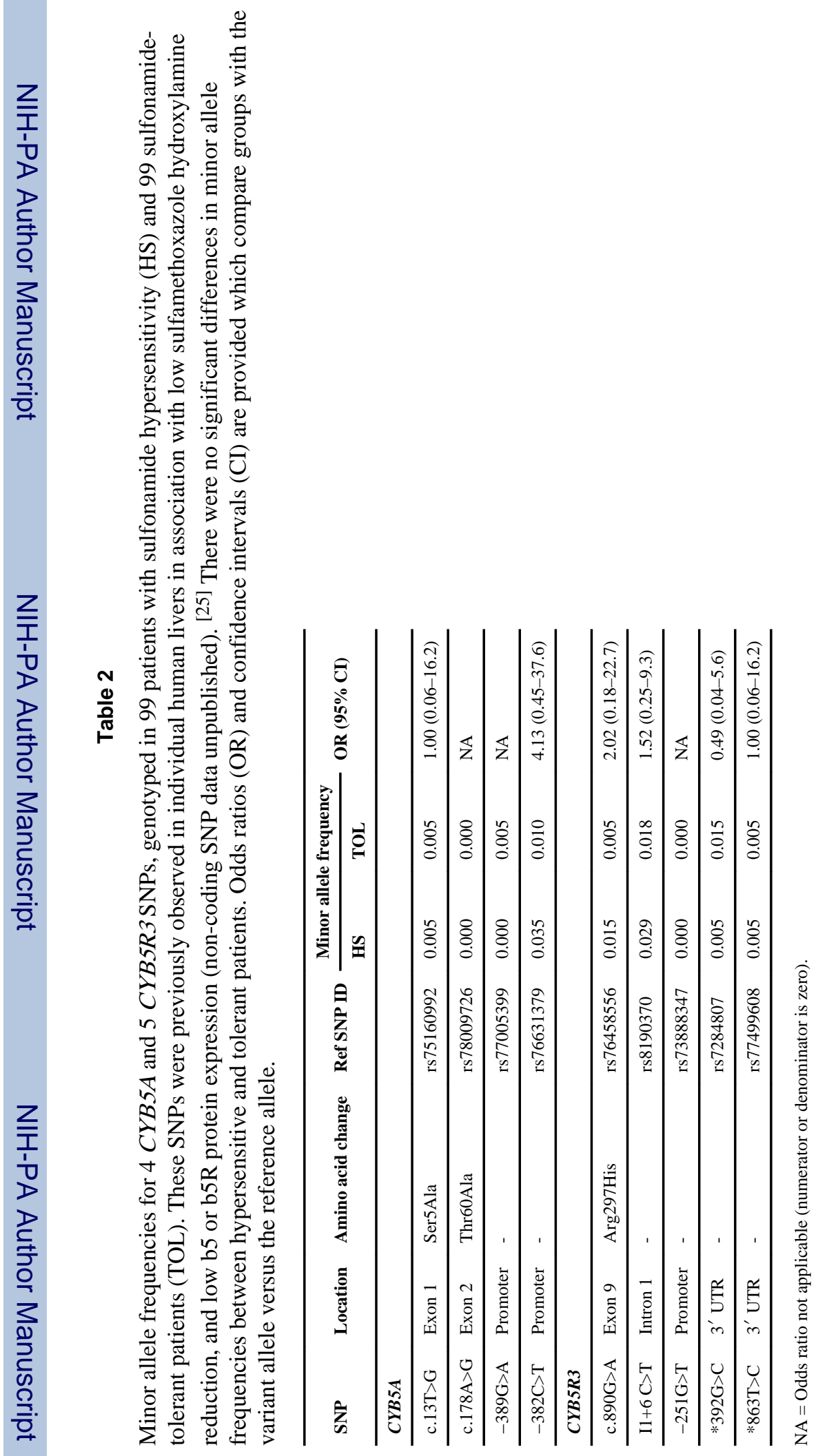




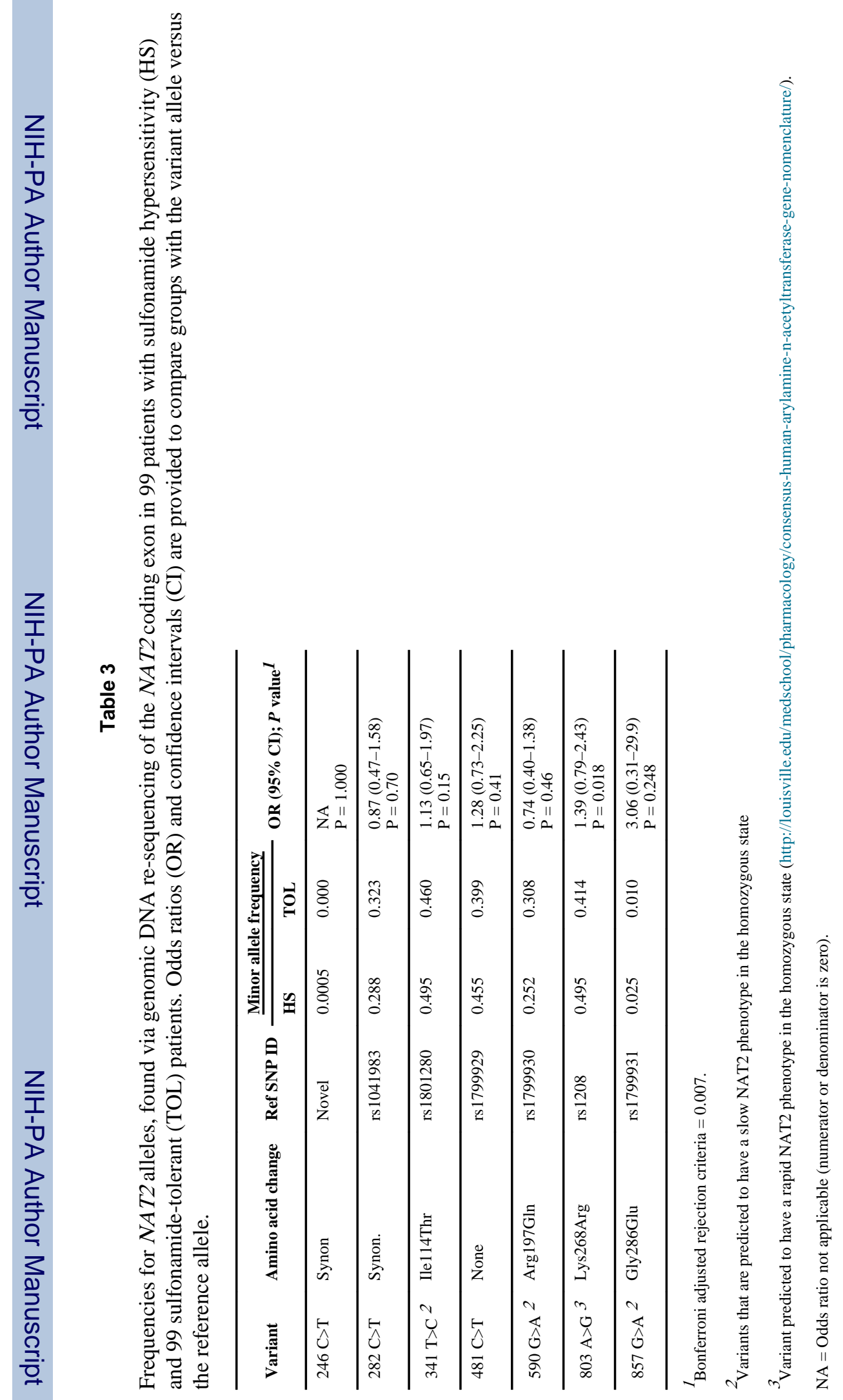




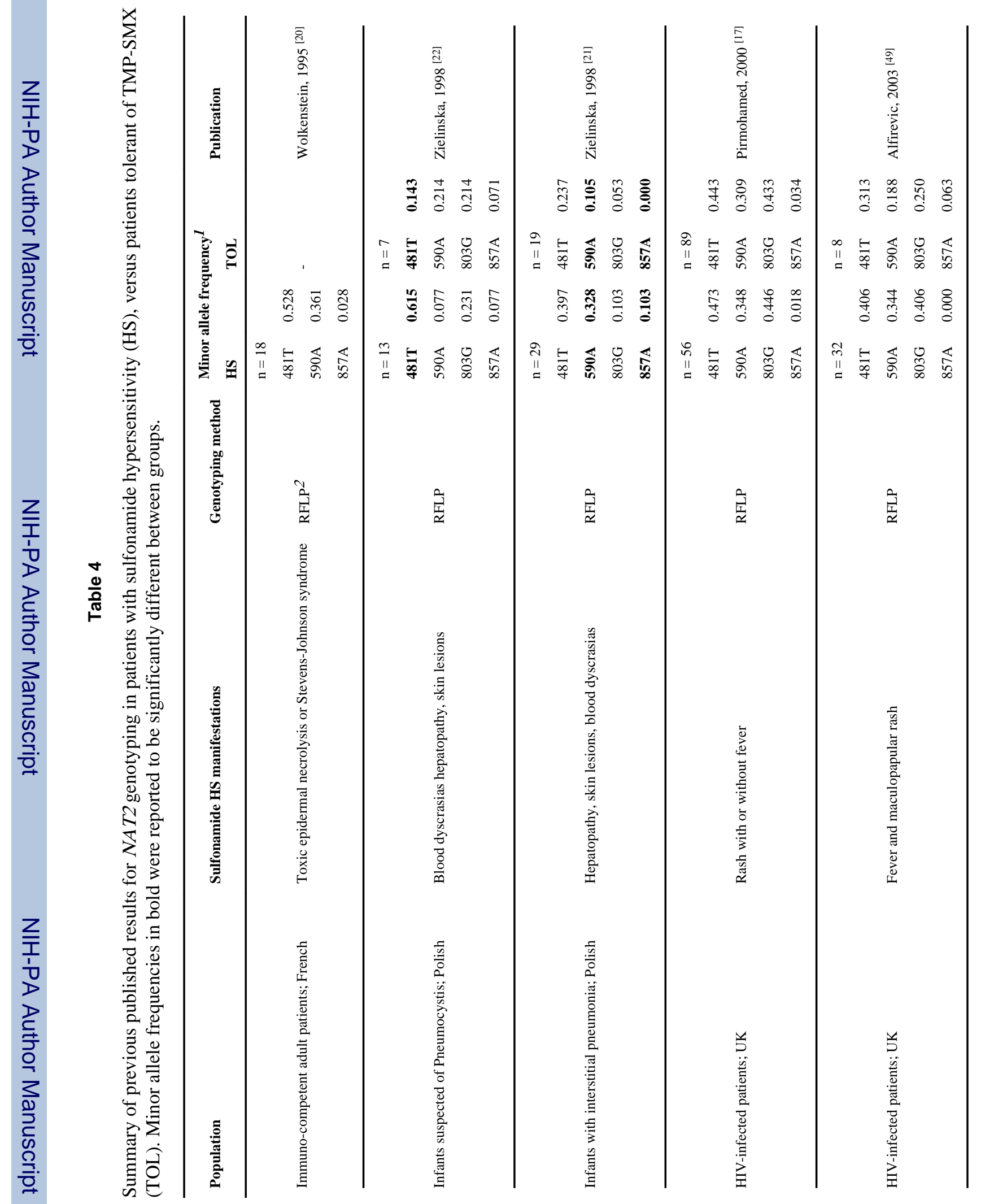


Sacco et al.

Page 15

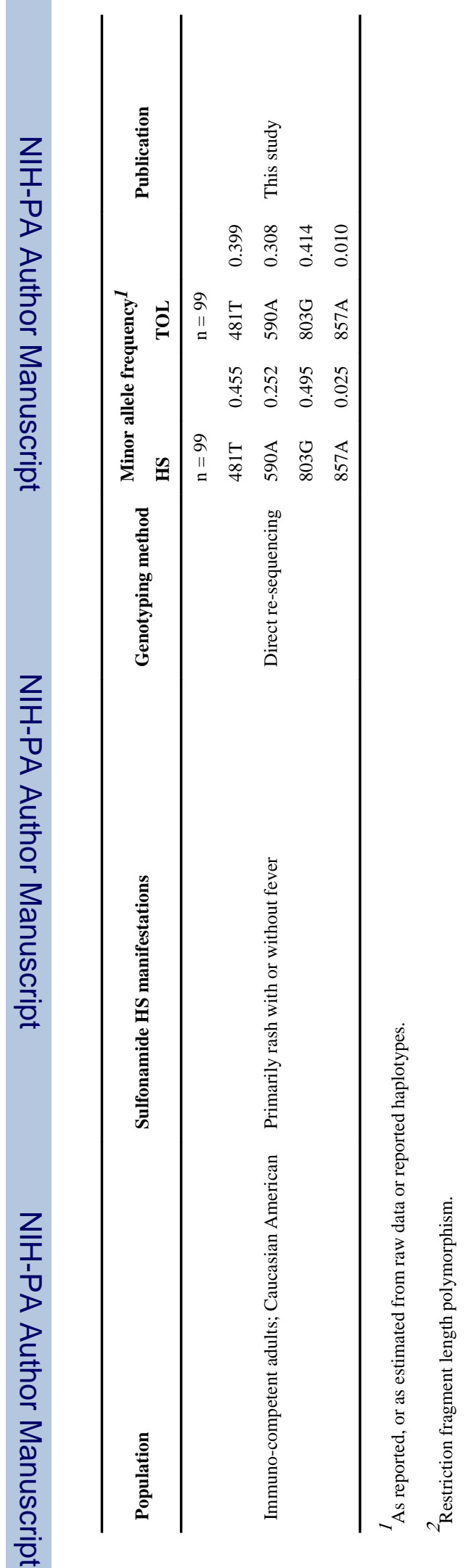

Pharmacogenet Genomics. Author manuscript; available in PMC 2013 April 08. 